\title{
Breast cancer screening: in the era of personalized medicine, age is just a number
}

\author{
Andrea Cozzi ${ }^{1}$, Simone Schiaffino ${ }^{2}$, Paolo Giorgi Rossi ${ }^{3}$, Francesco Sardanelli $^{1,2}$ \\ ${ }^{1}$ Department of Biomedical Sciences for Health, Università degli Studi di Milano, Milano, Italy; ${ }^{2}$ Unit of Radiology, IRCCS Policlinico San Donato, \\ San Donato Milanese, Italy; ${ }^{3}$ Epidemiology Unit, Azienda USL - IRCCS di Reggio Emilia, Reggio Emilia, Italy \\ Correspondence to: Dr. Andrea Cozzi, MD. Department of Biomedical Sciences for Health, Università degli Studi di Milano, Via Mangiagalli 31, \\ 20133 Milano, Italy. Email: andrea.cozzi1@unimi.it.
}

Comment on: Mukama T, Kharazmi E, Xu X, Sundquist K, Sundquist J, Brenner H, Fallah M. Risk-Adapted Starting Age of Screening for Relatives of Patients With Breast Cancer. JAMA Oncol 2019;6:68-74.

Submitted Aug 12, 2020. Accepted for publication Aug 24, 2020.

doi: 10.21037/qims-2020-26

View this article at: http://dx.doi.org/10.21037/qims-2020-26

"The great end of life is not knowledge but action."-Thomas Henry Huxley.

While breast cancer screening has a long and established history dating back to the 1960 s, screening programs still allow for little to none personalization, both when considering the choice of the imaging technique and the age boundaries, save for specific groups of highrisk women (1). This almost "one-size-fits-all" paradigm currently characterizes most European and North American screening strategies (1-4), with only few exceptions $(5,6)$.

A study by Mukama et al. (7) recently published in FAMA Oncology under the title "Risk-Adapted Starting Age of Screening for Relatives of Patients With Breast Cancer", aimed to improve and refine the age-related side of screening strategies for women outside the restricted high-risk category. By analyzing data from more than 5 million women born from 1932 onwards and included in the Swedish breast cancer screening registry from 1958 to 2015, the authors stratified women in 15 categories according to the number of their first- and second-degree relatives with a proved diagnosis of breast cancer, then they calculated how much each woman should bring forward or delay the beginning of her screening examinations to match the average 10 -year cumulative breast cancer risk at which screening is currently recommended to begin in the general population $(7,8)$. Of note, increasingly earlier risk-adapted starting ages are already suggested by this study when a woman has only one second-degree relative with breast cancer (7).

When compared with guidelines that recommend a screening mammography starting age of 50 years-such as the ones from the US Preventive Services Task Force (3) and the International Agency for Research on Cancer (2), widely adopted also in European countries-starting ages calculated by Mukama et al. (7) would call for a 5-year-earlier start (i.e., 45 years of age) in women with no more than one second-degree relative with breast cancer and as much as a 24-year-earlier start (i.e., 26 years of age) in a woman that has at least a first-degree relative and a second-degree relative diagnosed with breast cancer before age 40 . These differences are of course curtailed when a 45 years screening starting age is considered, as suggested for example by the American Cancer Society guidelines (4) or, albeit with a conditional recommendation, by the European Commission Initiative on Breast Cancer (1): if a woman has no more than a second-degree relative with breast cancer, a 3 -yearearlier start would be recommended, while a 20-year-earlier start would be recommended for a woman that has at least a first-degree relative and a second-degree relative diagnosed with breast cancer before age 40 .

Two main points need to be clarified. First, all aforementioned thresholds are unvaryingly based on data obtained from the general population. Second, when Mukama et al. (7) compared their 15 risk-adapted starting ages to equally risk-tiered guidelines, such as the ones issued by the American 
College of Radiology $(5,6)$, with recommended screening starting ages varying from 25 years (women with one firstdegree relative and one or more second-degree relatives with breast cancer) to 40 years (women with no family history or women with no first-degree relatives with breast cancer), they found that an earlier start was to be recommended only in 5 out of 15 categories, with only one category being assigned a $>5$ years anticipation, i.e. women with 2 or more first-degree relatives with a diagnosis of breast cancer before age 40, with a 7-year anticipation. Compared to the risk-tiered American College of Radiology guidelines (5,6), Mukama et al. (7) calculations would result in a postponement of the screening starting age in 10 out of 15 categories, with a deferral as high as 6 years for women with no second-degree relatives with breast cancer and no more than a first-degree relative with a diagnosis of breast cancer after age 49 . Notably, the authors also recommend short deferrals in the screening starting age for the largest category of women, those without family history, with a 1-year postponement when compared to guidelines that recommend to begin screening at 40 or 45 years of age, and a 2-year postponement compared to guidelines that recommend a 50 years screening starting age. These and other adjustments proposed by members of the same research group in two recently published papers $(9,10)$ represent a contribution to evidence-based decision making. However, it should be noted that these adjustments are still driven by just a couple of variables, i.e., family history $(7,10)$ or reproductive profile (9), therefore remaining far from a multifactorial tailoring of screening strategies $(11,12)$. Even if they are backed by a population-based analysis, these adjustments would need to be validated in large prospective trials before being introduced in routine screening practice. To date, they seem more useful to orientate a research agenda rather than to shape immediately applicable policies. A potentially more viable application of these findings would see them guide the referral of selected subsets of a population to genetic counselling and, when appropriate, to genetic testing (13). As already envisaged by other authors (8), the best contribution of these findings could come from an integration of family history into currently more comprehensive prediction models such as the last version of Tyrer-Cuzick model [also including breast density (14)], the Gail model, or the Breast Cancer Surveillance Consortium model $(15,16)$, which could convey to such a large scale counselling a better chance of being practically feasible. Importantly, the use of a multivariate model instead of an exclusive reliance on family history would also allow to overcome the effect of ongoing demographic and socioeconomic transformations that, especially in European and North American countries, see the ubiquitous rise of smaller families with fewer and fewer first- and seconddegree relatives, making the use of family history as a risk factor very challenging.

The recent findings from Mukama et al. $(7,10)$ could be usefully viewed as elements of the larger picture represented by the personalization of breast cancer screening $(8,11,12)$. In addition, we should consider that the outcome efficacy of screening strategies is probably not the same for women with different breast cancer risk profiles, due to at least three reasons: (I) the still unascertained assumption that individual risk for each breast cancer subtype proportionally increases with age $(17,18)$; (II) the variability of breast cancer prognosis according to age and other comorbidities (19-21); (III) the large difference in accuracy exhibited by different screening tools $(1,22,23)$.

This last point is indeed the most complex hurdle in the path towards personalized breast cancer screening, as demonstrated for example by the design of the "My Personalized Breast Screening (MyPeBS)" study (24), including more than 85,000 women across Italy, France, Israel, Belgium, and the United Kingdom. Its key primary objective is to assess the non-inferiority of a risk-stratified screening strategy by evaluating the incidence of stage II or higher breast cancer, while the key secondary objective is to ascertain the superiority of the risk-based screening strategy compared to standard strategy in reducing the incidence of stage II or higher breast cancer. In the experimental arm, family history, genotyping with polygenic risk score, mammographic breast density, previous history of benign breast biopsy, and personal hormonal and reproductive history are not only used to propose a tailored schedule (25) but also to regulate the adoption of different imaging tools. Indeed, this tiered use of different imaging modalities and techniques is guided by the evidence on screening with tomosynthesis (26-29), hand-held (30-32) or automated breast ultrasound (33-36), and contrast-enhanced breast magnetic resonance imaging (CE-MRI) (37-40) alongside digital mammography (41). The introduction of these modalities and of their refinements-e.g., non-contrastenhanced MRI with diffusion weighted imaging (42-44), abbreviated CE-MRI (45-47), and contrast-enhanced mammography (CEM) (48-50)-represents indeed a composite answer to the historical diagnostic shortcomings of purely morphological imaging such as screen film and digital mammography, tomosynthesis and ultrasound. These 
shortcomings, particularly the reduced sensitivity of digital mammography in dense breasts (41), are indeed the most conspicuous hindrance to a direct implementation of riskadapted strategies such as the ones proposed by Mukama et al. $(7,9,10)$. Of note, annual organized screening with a combination of digital mammography/tomosynthesis and hand-held/automated breast ultrasound in young women may lead, as already demonstrated in small scale studies, to a high number of false positive findings and unnecessary biopsies (51,52). Moreover, in the case of women with familiar history of breast cancer, a progressively earlier beginning of annual screening mammography could also be at odds with precautions against the risk of radiation induced breast cancer (53), which may indeed concern not only the restricted population of proven $B R C A$ mutation carriers but also women with an increasingly prominent familiar history of breast cancer.

Considering the still limited availability of CE-MRI screening (37) — even in its abbreviated form (47) —and intrinsic concern on gadolinium retention after multiple administrations (54), a compromise to ensure that advancements in the epidemiological tailoring of breast cancer screening are supported by a corresponding increase in the diagnostic performance of imaging tools could be represented by CEM, which retains the ability to provide morphofunctional information at much lower costs than CE-MRI (55), with comparable performance (56) and higher patient preference (57). Higher CEM tolerability would also favor its acceptance by women, potentially overcoming the only $59 \%$ uptake of CE-MRI screening reported by the DENSE Trial (40). In the meanwhile, new solutions are coming from the integration of artificial intelligence in established screening strategies such as digital mammography (58), while dual-energy mammographic techniques may also grant breast tissue characterization without contrast injection (59).

Future breast cancer screening will surely be different from that of the last decades. The mainstream approach should be a woman-centered multifactorial one, open to innovation coming from advances in biological knowledge and technological developments, supported by a multidisciplinary contribution of epidemiologists, radiologists, and oncologists, potentially also including women advocacy groups.

\section{Acknowledgments}

Funding: None.

\section{Footnote}

Provenance and Peer Review: This article was commissioned by the editorial office, Quantitative Imaging in Medicine and Surgery. The article did not undergo external peer review.

Conflicts of Interest: All authors have completed the ICMJE uniform disclosure form (available at http://dx.doi. org/10.21037/qims-2020-26). SS reports non-financial support from Bracco Imaging, personal fees from General Electric Healthcare, outside the submitted work. PGR reports: as principal investigator of an independent study, funded by the Italian Ministry of Health, I conducted negotiations with Roche Diagnostics, Hologic, and Becton Dickinson, to obtain reagents at reduced price or for free. I am the Italian coordinator of the MyPeBS trial and I was involved in the design of the Tailored Breast Screening Trial. I published opinions, based on both evidence and personal views, in favor of organized screening programs instead of opportunistic screening. FS reports grants from Horizon 2020 project funding, grants and personal fees from General Electric Healthcare, grants and personal fees from Bracco Group, grants and personal fees from Bayer Healthcare, outside the submitted work. The other author has no conflicts of interest to declare.

Open Access Statement: This is an Open Access article distributed in accordance with the Creative Commons Attribution-NonCommercial-NoDerivs 4.0 International License (CC BY-NC-ND 4.0), which permits the noncommercial replication and distribution of the article with the strict proviso that no changes or edits are made and the original work is properly cited (including links to both the formal publication through the relevant DOI and the license). See: https://creativecommons.org/licenses/by-nc-nd/4.0/.

\section{References}

1. Schünemann HJ, Lerda D, Quinn C, Follmann M, Alonso-Coello P, Rossi PG, Lebeau A, Nyström L, Broeders M, Ioannidou-Mouzaka L, Duffy SW, Borisch B, Fitzpatrick P, Hofvind S, Castells X, Giordano L, Canelo-Aybar C, Warman S, Mansel R, Sardanelli F, Parmelli E, Gräwingholt A, Saz-Parkinson Z. Breast Cancer Screening and Diagnosis: A Synopsis of the European Breast Guidelines. Ann Intern Med 2020;172:46-56.

2. Armaroli P, Villain P, Suonio E, Almonte M, Anttila A, 
Atkin WS, Dean PB, de Koning HJ, Dillner L, Herrero R, Kuipers EJ, Lansdorp-Vogelaar I, Minozzi S, Paci E, Regula J, Törnberg S, Segnan N. European Code against Cancer, 4th Edition: Cancer screening. Cancer Epidemiol 2015;39:S139-S152.

3. Siu AL. Screening for Breast Cancer: U.S. Preventive Services Task Force Recommendation Statement. Ann Intern Med 2016;164:279-96.

4. Smith RA, Andrews KS, Brooks D, Fedewa SA, Manassaram-Baptiste D, Saslow D, Wender RC. Cancer screening in the United States, 2019: A review of current American Cancer Society guidelines and current issues in cancer screening. CA Cancer J Clin 2019;69:184-210.

5. Monticciolo DL, Newell MS, Hendrick RE, Helvie MA, Moy L, Monsees B, Kopans DB, Eby PR, Sickles EA. Breast Cancer Screening for Average-Risk Women: Recommendations From the ACR Commission on Breast Imaging. J Am Coll Radiol 2017;14:1137-43.

6. Monticciolo DL, Newell MS, Moy L, Niell B, Monsees B, Sickles EA. Breast Cancer Screening in Women at Higher-Than-Average Risk: Recommendations From the ACR. J Am Coll Radiol 2018;15:408-14.

7. Mukama T, Kharazmi E, Xu X, Sundquist K, Sundquist J, Brenner H, Fallah M. Risk-Adapted Starting Age of Screening for Relatives of Patients With Breast Cancer. JAMA Oncol 2019;6:68-74.

8. Gierach GL, Choudhury PP, García-Closas M. Toward Risk-Stratified Breast Cancer Screening: Considerations for Changes in Screening Guidelines. JAMA Oncol 2019;6:31-3.

9. Mukama T, Fallah M, Tian Y, Sundquist K, Sundquist J, Brenner H, Kharazmi E. Risk-tailored starting age of breast cancer screening based on women's reproductive profile: A nationwide cohort study. Eur J Cancer 2020;124:207-13.

10. Mukama T, Kharazmi E, Sundquist K, Sundquist J, Brenner H, Fallah M. Familial risk of breast cancer by dynamic, accumulative, and static definitions of family history. Cancer 2020;126:2837-48.

11. Onega T, Beaber EF, Sprague BL, Barlow WE, Haas JS, Tosteson AN, D Schnall M, Armstrong K, Schapira MM, Geller B, Weaver DL, Conant EF. Breast cancer screening in an era of personalized regimens: A conceptual model and National Cancer Institute initiative for risk-based and preference-based approaches at a population level. Cancer 2014;120:2955-64.

12. Morman NA, Byrne L, Collins C, Reynolds K, Bell JG. Breast Cancer Risk Assessment at the Time of Screening
Mammography: Perceptions and Clinical Management Outcomes for Women at High Risk. J Genet Couns 2017;26:776-84.

13. Piccinin C, Panchal S, Watkins N, Kim RH. An update on genetic risk assessment and prevention: the role of genetic testing panels in breast cancer. Expert Rev Anticancer Ther 2019;19:787-801.

14. Brentnall AR, Cuzick J, Buist DSM, Bowles EJA. Long-term Accuracy of Breast Cancer Risk Assessment Combining Classic Risk Factors and Breast Density. JAMA Oncol 2018;4:e180174.

15. Amir E. Evaluation of breast cancer risk assessment packages in the family history evaluation and screening programme. J Med Genet 2003;40:807-14.

16. Cintolo-Gonzalez JA, Braun D, Blackford AL, Mazzola E, Acar A, Plichta JK, Griffin M, Hughes KS. Breast cancer risk models: a comprehensive overview of existing models, validation, and clinical applications. Breast Cancer Res Treat 2017;164:263-84.

17. Barnard ME, Boeke CE, Tamimi RM. Established breast cancer risk factors and risk of intrinsic tumor subtypes. Biochim Biophys Acta 2015;1856:73-85.

18. Prat A, Pineda E, Adamo B, Galván P, Fernández A, Gaba L, Díez M, Viladot M, Arance A, Muñoz M. Clinical implications of the intrinsic molecular subtypes of breast cancer. The Breast 2015;24:S26-S35.

19. Phung MT, Tin Tin S, Elwood JM. Prognostic models for breast cancer: a systematic review. BMC Cancer 2019;19:230.

20. Tang W, Mu D, Han L, Guo X, Han B, Song D. Screening of Clinical Factors Related to Prognosis of Breast Cancer Based on the Cox Proportional Risk Model. J Comput Biol 2020. doi: 10.1089/ cmb.2019.0110. [Epub ahead of print].

21. Wong FY, Tham WY, Nei WL, Lim C, Miao H. Age exerts a continuous effect in the outcomes of Asian breast cancer patients treated with breast-conserving therapy. Cancer Commun (Lond) 2018;38:39.

22. Sardanelli F, Aase HS, Álvarez M, Azavedo E, Baarslag HJ, Balleyguier C, Baltzer PA, Beslagic V, Bick U, Bogdanovic-Stojanovic D, Briediene R, Brkljacic B, Camps Herrero J, Colin C, Cornford E, Danes J, de Geer G, Esen G, Evans A, Fuchsjaeger MH, Gilbert FJ, Graf O, Hargaden G, Helbich TH, HeywangKöbrunner SH, Ivanov V, Jónsson Á, Kuhl CK, Lisencu EC, Luczynska E, Mann RM, Marques JC, Martincich L, Mortier M, Müller-Schimpfle M, Ormandi K, Panizza P, Pediconi F, Pijnappel RM, Pinker K, Rissanen T, Rotaru 
N, Saguatti G, Sella T, Slobodníková J, Talk M, Taourel P, Trimboli RM, Vejborg I, Vourtsis A, Forrai G. Position paper on screening for breast cancer by the European Society of Breast Imaging (EUSOBI) and 30 national breast radiology bodies from Austria, Belgium, Bosnia and Herzegovina, Bulgaria, Croatia, Czech Republic, Denmark, Estonia, Finland, France, Germany, Greece, Hungary, Iceland, Ireland, Italy, Israel, Lithuania, Moldova, The Netherlands, Norway, Poland, Portugal, Romania, Serbia, Slovakia, Spain, Sweden, Switzerland and Turkey. Eur Radiol 2017;27:2737-43.

23. Pediconi F, Galati F. Breast cancer screening programs: does one risk fit all? Quant Imaging Med Surg 2020;10:886-90.

24. Delaloge S, Giorgi Rossi P, Balleyguier C, Guindy M, Burrion JB, Gilbert FJ. My Personalized Breast Screening (MyPeBS) - ClinicalTrials.gov Identifier NCT03672331. 2018. Available online: https://clinicaltrials.gov/show/ NCT03672331. Accessed August 8, 2020.

25. Carbonaro LA, Rizzo SS, Schiaffino S, Pisani Mainini A, Berger N, Trimboli RM, Sardanelli F. Biennial screening mammography: How many women ask for more? Estimate of the interval mammogram rate in an organised population-based screening programme. Radiol Med 2020. doi: 10.1007/s11547-020-01238-3. [Epub ahead of print].

26. Pattacini P, Nitrosi A, Giorgi Rossi P, Iotti V, Ginocchi V, Ravaioli S, Vacondio R, Braglia L, Cavuto S, Campari C. Digital Mammography versus Digital Mammography Plus Tomosynthesis for Breast Cancer Screening: The Reggio Emilia Tomosynthesis Randomized Trial. Radiology 2018;288:375-85.

27. Bahl M, Gaffney S, McCarthy AM, Lowry KP, Dang PA, Lehman CD. Breast Cancer Characteristics Associated with 2D Digital Mammography versus Digital Breast Tomosynthesis for Screening-detected and Interval Cancers. Radiology 2018;287:49-57.

28. Conant EF, Barlow WE, Herschorn SD, Weaver DL, Beaber EF, Tosteson ANA, Haas JS, Lowry KP, Stout NK, Trentham-Dietz A, DiFlorio-Alexander RM, Li CI, Schnall MD, Onega T, Sprague BL. Association of Digital Breast Tomosynthesis vs Digital Mammography With Cancer Detection and Recall Rates by Age and Breast Density. JAMA Oncol 2019;5:635-42.

29. Hovda T, Holen ÅS, Lång K, Albertsen JL, Bjørndal H, Brandal SHB, Sahlberg KK, Skaane P, Suhrke P, Hofvind S. Interval and Consecutive Round Breast Cancer after Digital Breast Tomosynthesis and Synthetic
2D Mammography versus Standard 2D Digital Mammography in BreastScreen Norway. Radiology 2020;294:256-64.

30. Geisel J, Raghu M, Hooley R. The Role of Ultrasound in Breast Cancer Screening: The Case for and Against Ultrasound. Semin Ultrasound CT MR 2018;39:25-34.

31. Brem RF, Lenihan MJ, Lieberman J, Torrente J. Screening Breast Ultrasound: Past, Present, and Future. AJR Am J Roentgenol 2015;204:234-40.

32. Butler RS, Hooley RJ. Screening Breast Ultrasound: Update After 10 Years of Breast Density Notification Laws. AJR Am J Roentgenol 2020;214:1424-35.

33. Vourtsis A, Kachulis A. The performance of $3 \mathrm{D}$ ABUS versus HHUS in the visualisation and BI-RADS characterisation of breast lesions in a large cohort of 1,886 women. Eur Radiol 2018;28:592-601.

34. Mussetto I, Gristina L, Schiaffino S, Tosto S, Raviola E, Calabrese M. Breast ultrasound: automated or handheld? Exploring patients' experience and preference. Eur Radiol Exp 2020;4:12.

35. Schiaffino S, Gristina L, Tosto S, Massone E, De Giorgis S, Garlaschi A, Tagliafico A, Calabrese M. The value of coronal view as a stand-alone assessment in women undergoing automated breast ultrasound. Radiol Med 2020. doi: 10.1007/s11547-020-01250-7. [Epub ahead of print].

36. Brem RF, Tabár L, Duffy SW, Inciardi MF, Guingrich JA, Hashimoto BE, Lander MR, Lapidus RL, Peterson MK, Rapelyea JA, Roux S, Schilling KJ, Shah BA, Torrente J, Wynn RT, Miller DP. Assessing Improvement in Detection of Breast Cancer with Threedimensional Automated Breast US in Women with Dense Breast Tissue: The SomoInsight Study. Radiology 2015;274:663-73.

37. Mann RM, Cho N, Moy L. Breast MRI: State of the Art. Radiology 2019;292:520-36.

38. Saadatmand S, Geuzinge HA, Rutgers EJT, Mann RM, de Roy van Zuidewijn DBW, Zonderland HM, Tollenaar RAEM, Lobbes MBI, Ausems MGEM, van 't Riet M, Hooning MJ, Mares-Engelberts I, Luiten EJT, Heijnsdijk EAM, Verhoef C, Karssemeijer N, Oosterwijk JC, Obdeijn IM, de Koning HJ, Tilanus-Linthorst MMA, van Deurzen CH, Loo CE, Wesseling J, Schlooz-Vries M, van der Meij S, Mesker W, Keymeulen K, Contant C, Madsen E, Koppert LB, Rothbarth J, Veldhuis WB, Witkamp AJ, Tetteroo E, de Monye C, van Rosmalen MM, Remmelzwaal J, Gort HBW, Roi-Antonides R, Wasser MN, van Druten E. MRI versus mammography 
for breast cancer screening in women with familial risk (FaMRIsc): a multicentre, randomised, controlled trial. Lancet Oncol 2019;20:1136-47.

39. Sippo DA, Burk KS, Mercaldo SF, Rutledge GM, Edmonds C, Guan Z, Hughes KS, Lehman CD. Performance of Screening Breast MRI across Women with Different Elevated Breast Cancer Risk Indications. Radiology 2019;292:51-9.

40. Bakker MF, de Lange SV, Pijnappel RM, Mann RM, Peeters PHM, Monninkhof EM, Emaus MJ, Loo CE, Bisschops RHC, Lobbes MBI, de Jong MDF, Duvivier KM, Veltman J, Karssemeijer N, de Koning HJ, van Diest PJ, Mali WPTM, van den Bosch MAAJ, Veldhuis WB, van Gils CH. Supplemental MRI Screening for Women with Extremely Dense Breast Tissue. N Engl J Med 2019;381:2091-102.

41. Pisano ED, Gatsonis C, Hendrick E, Yaffe M, Baum JK, Acharyya S, Conant EF, Fajardo LL, Bassett L, D’Orsi C, Jong R, Rebner M. Diagnostic Performance of Digital versus Film Mammography for Breast-Cancer Screening. N Engl J Med 2005;353:1773-83.

42. Iima M, Honda M, Sigmund EE, Ohno Kishimoto A, Kataoka M, Togashi K. Diffusion MRI of the breast: Current status and future directions. J Magn Reson Imaging 2020;52:70-90.

43. Amornsiripanitch N, Bickelhaupt S, Shin HJ, Dang M, Rahbar H, Pinker K, Partridge SC. Diffusionweighted MRI for Unenhanced Breast Cancer Screening. Radiology 2019;293:504-20.

44. Rotili A, Trimboli RM, Penco S, Pesapane F, Tantrige P, Cassano E, Sardanelli F. Double reading of diffusionweighted magnetic resonance imaging for breast cancer detection. Breast Cancer Res Treat 2020;180:111-20.

45. Greenwood HI. Abbreviated protocol breast MRI: The past, present, and future. Clin Imaging 2019;53:169-73.

46. Comstock CE, Gatsonis C, Newstead GM, Snyder BS, Gareen IF, Bergin JT, Rahbar H, Sung JS, Jacobs C, Harvey JA, Nicholson MH, Ward RC, Holt J, Prather A, Miller KD, Schnall MD, Kuhl CK. Comparison of Abbreviated Breast MRI vs Digital Breast Tomosynthesis for Breast Cancer Detection Among Women With Dense Breasts Undergoing Screening. JAMA 2020;323:746-56.

47. Kuhl CK. Abbreviated Magnetic Resonance Imaging (MRI) for Breast Cancer Screening: Rationale, Concept, and Transfer to Clinical Practice. Annu Rev Med 2019;70:501-19.

48. Zanardo M, Cozzi A, Trimboli RM, Labaj O, Monti CB, Schiaffino S, Carbonaro LA, Sardanelli F. Technique, protocols and adverse reactions for contrast-enhanced spectral mammography (CESM): a systematic review. Insights Imaging 2019;10:76.

49. Cozzi A, Schiaffino S, Sardanelli F. The emerging role of contrast-enhanced mammography. Quant Imaging Med Surg 2019;9:2012-8.

50. Ghaderi KF, Phillips J, Perry H, Lotfi P, Mehta TS. Contrast-enhanced Mammography: Current Applications and Future Directions. RadioGraphics 2019;39:1907-20.

51. Sardanelli F, Trimboli RM, Tot T. Expert Review of Breast Pathology in Borderline Lesions. JAMA Oncol 2018;4:1325-6.

52. Nelson HD, Pappas M, Cantor A, Griffin J, Daeges M, Humphrey L. Harms of Breast Cancer Screening: Systematic Review to Update the 2009 U.S. Preventive Services Task Force Recommendation. Ann Intern Med 2016;164:256-67.

53. Colin C, Foray N, Di Leo G, Sardanelli F. Radiation induced breast cancer risk in BRCA mutation carriers from low-dose radiological exposures: a systematic review. Radioprotection 2017;52:231-40.

54. Sardanelli F, Cozzi A, Trimboli RM, Schiaffino S. Gadolinium Retention and Breast MRI Screening: More Harm Than Good? AJR Am J Roentgenol 2020;214:324-7.

55. Patel BK, Gray RJ, Pockaj BA. Potential Cost Savings of Contrast-Enhanced Digital Mammography. AJR Am J Roentgenol 2017;208:W231-7.

56. Xiang W, Rao H, Zhou L. A meta-analysis of contrastenhanced spectral mammography versus MRI in the diagnosis of breast cancer. Thorac Cancer 2020;11:1423-32.

57. Hobbs MM, Taylor DB, Buzynski S, Peake RE. Contrastenhanced spectral mammography (CESM) and contrast enhanced MRI (CEMRI): Patient preferences and tolerance. J Med Imaging Radiat Oncol 2015;59:300-5.

58. McKinney SM, Sieniek M, Godbole V, Godwin J, Antropova N, Ashrafian H, Back T, Chesus M, Corrado GC, Darzi A, Etemadi M, Garcia-Vicente F, Gilbert FJ, Halling-Brown M, Hassabis D, Jansen S, Karthikesalingam A, Kelly CJ, King D, Ledsam JR, Melnick D, Mostofi H, Peng L, Reicher JJ, RomeraParedes B, Sidebottom R, Suleyman M, Tse D, Young KC, De Fauw J, Shetty S. International evaluation of an AI system for breast cancer screening. Nature 2020;577:89-94.

59. Drukker K, Giger ML, Joe BN, Kerlikowske K, Greenwood H, Drukteinis JS, Niell B, Fan B, Malkov 
S, Avila J, Kazemi L, Shepherd J. Combined Benefit of Quantitative Three-Compartment Breast Image Analysis and Mammography Radiomics in the Classification

Cite this article as: Cozzi A, Schiaffino S, Giorgi Rossi P, Sardanelli F. Breast cancer screening: in the era of personalized medicine, age is just a number. Quant Imaging Med Surg 2020;10(12):2401-2407. doi: 10.21037/qims-2020-26 of Breast Masses in a Clinical Data Set. Radiology 2019;290:621-8. 